\title{
An Investigation on Breast Feeding Practices in Normal Newborn Babies During Institutional Deliveries in Bhopal District of Madhya Pradesh
}

\author{
Chandramohan Reddy. $\mathrm{S}^{1}$, Dharna Ajay Shobhane ${ }^{2}$, Manjusha Goel ${ }^{3}$ and \\ Rashmi Dwivedi ${ }^{4}$ \\ 1. Assistant Professor in Pediatrics, DM-Wayanad Institute of Medical Sciences (DM-WIMS), Meppadi- \\ 673577, Kerala State, India. \\ 2. Senior Resident in Pediatrics, DM-Wayanad Institute of Medical Sciences (DM-WIMS), Meppadi-673577, \\ Kerala State, India \\ 3. Associate Professor, Dept. of Pediatrics, Gandhi Medical College, Bhopal, Madhya Pradesh, India \\ 4. Professor and Head, Dept. of Pediatrics, Gandhi Medical College, Bhopal, Madhya Pradesh, India
}

\begin{abstract}
The Present study makes an attempt to analyze the Breast feeding practices in normal Newborn babies in institutional Deliveries and also to investigate time of initiation of Breast feeding practices and type of feeds given to the normal newborn babies in Institutional Deliveries. The study was conducted in the Department of Paediatrics \& Obstetric and Gynaecology, Gandhi Medical College, Bhopal. The study was based on primary data with help of observational study during the period from August 2008 to September 2009 with sample size 500 cases. The findings of the study revealed that, distribution of newborns according to the time of initiation of breast feeding was found to be in high within half an hour to five hours duration. The new born male babies were high (77.9 per cent) when compared to female babies (68.49 per cent) during half an hour to five hours duration. Further, study results on type of delivery revealed that, 82.6 percent of babies were delivered by normal vaginal delivery (NVD) and 17.4 percent of babies were delivered by lower segment caesarean section (LSCS). The Study also focused on type of pre-lacteal feeds given to the newborns, the outcome the study shows that, more than 50 percent of mothers practiced pre-lacteal feeds of one sort or the other which includes Cow's milk (39.8\%), Tea (27.2\%), Honey (14.9\%), Goat's Milk (11.11\%) and Glucose water (6.89\%). Hence, the study suggests that, breastfeeding should be made to all normal newborns (including those born by caesarean section) as early as possible after birth, ideally within half an hour to five hours duration. The Colostrum, which is secreted within first 2-3 days, must not be leftover but should be fed to newborn as it contains high concentration of defensive immunoglobulin's and cells which provides an optimal nutrition to child and prevent from infections. Health service providers have significant role in not only promoting optimal breast feeding practices but also in ensuring these practices are followed.
\end{abstract}

Key words: Postnatal Wards, breast Feeding practices, Time of initiation and pre-lacteal feeds.

\section{Introduction}

A child's life provides a decisive window initial for 2 years, which has impacts on opportunity for appropriate growth, development and child survival. To deserve suitable growth \& development and child survival it's critical to uphold optimal infant feeding practices of new borns. The practice of Breastfeeding has been publicized worldwide frequently to be the solitary most efficient way to prevent infant and young child mortality. Breastfeeding, plays a vital role in children's health and development, and appreciably benefits the health of mothers by reducing bleeding postpartum and risk of certain types of cancer. In the early hours and exclusive breastfeeding progress newborn care and reduces neonatal mortality, which represents the majority proportion of infant deaths (World Alliance for Breastfeeding Action, 2012). The main reason for declining breast feeding is due to lack of non-availability of information to mothers, insufficient health care support, and incapability of the health care providers to help mothers experiencing breastfeeding difficulty are the core reason for declining breastfeeding rates. Conversely, mother's health is also very important during delivery. Mothers having body weight less than $38 \mathrm{kgs}$ and height less than $145 \mathrm{cms}$ during the their reproductive period are likely to be at risk during delivery and give birth to babies of low birth weight (Gopalan, 1989).

Due to lack of correct information and support women are susceptible to fall for commercially available hazardous feeding options. It is a simple matter to understand the practice of breastfeeding, women and baby need to be in close proximity with appropriate personal and equipped support. Apart from this, Support from family, community, workplace, health facility, emergency or legislations are indispensable during this term. Hence, with this background the present research paper makes an attempt to investigate following objectives: 1. To analyze the Breast feeding practices in normal Newborn babies in institutional Deliveries and 
2. To investigate time of initiation of Breast feeding practices and type of feeds given to the normal newborn babies in Institutional Deliveries.

\section{Materials and Methods}

The present study was conducted in the Department of Paediatrics \& Obstetric and Gynaecology, (Postnatal Wards), Gandhi Medical College, Bhopal (Tertiary Referral Hospital in Central India) - during August 2008 - September 2009. All married women in the age group of 21-36 years who have given birth to new babies born both by normal delivery as well as caesarean section were included in the study. A total of 500 cases were interviewed using a purposive sampling method with help of structured questionnaire including type of delivery, time of initiation of breast feeding after delivery, feeding practices adopted, awareness of importance of breast feeding and their source of information, postnatal care and other basic information related to study. Further, the collected information was coded and analysed using SPSS package (version 16.0) the output was expressed in percentage. The Pearson's chi-squared test $\left(\chi^{2}\right)$ was used for evaluating association between Sex of new born babies and Time of initiation of breast feeding variables. ' $\mathrm{P}$ ' value $<0.05$ was considered statistically significant.

\section{Result and Discussion}

Even though breast feeding is a widespread fact in India very few children are put to this practice immediately after birth. The study results revealed that, the distribution of newborns according to the sex among 500 samples, the majority were male babies accounted for 56.2 percent and 43.8 percent were female babies (Table.1). However, the results on distribution of newborns according to the time of initiation of breast feeding also revealed that, Only 10.6 percent of mothers initiated breastfeeding within half an hour of the birth in present study (Table.2). Around 77.9 percent (218 cases) of male babies started breast feeding within half an hour to five hours duration. Whereas female babies with 68.49 percent ( 150 cases) started breast feeding within half an hour to five hours duration. The study results revealed that, there is no significant correlation between the sex of the baby and time of initiation of breast feeding $(\mathrm{P}<0.05)$.

More or less similar observations were found by K Madhu et al (2009). Observed that only $44 \%$ of mothers initiated breastfeeding within 10 minutes in normal delivery and $38 \%$ with caesarean section. On an average there was delay of 2 to $3 \mathrm{hrs}$. in feeding. These findings are conformity with results found by Shrivastav et al (1994) observed in their study that only $0.5 \%$ women breastfed their babies within $6 \mathrm{hrs}$ and nearly $50 \%$ started after $48 \mathrm{hrs}$. And also in case of Luke C. Mullany et al (2008) observed that only 3.4\% were breast fed within the first hour after birth, but breastfeeding within the first hour (56.6\%) or first $48(83.1 \%)$ hours was more common. Akhter HH et al. (1998) also stated that, there was no discrimination between sexes for initiation of breast feeding after delivery.

The study on type of delivery results revealed that, the study group 82.6 percent of babies were delivered by normal vaginal delivery (NVD) and 17.4 percent of babies were delivered by lower segment caesarean section (LSCS) presented in table 3.

From the table. 4 it is evident that, 92.5 percent of newborns born by normal delivery were initiated Breastfeeding between half an hour to five hour duration, as compared to 49.33 percent of babies born by caesarean section. Only 12.6 percent of babies born by normal delivery initiated Breastfeeding within half an hour, whereas only 1.15 percent of babies born by caesarean section started breastfeeding immediately after birth. These results are conformity with Malek Batal and Boulghourjian (2005) observed in his study that only $86.7 \%$ initiated Breastfeeding few hours following delivery, while only $13.3 \%$ had initiated Breastfeeding two days later. Athavale et al (2004) observed that the average time of initiation of breast feeding was $12.8 \mathrm{hrs}$ against $23 \mathrm{hrs}$ for those with caesarean section. The Median time of initiation of breastfeeding was $2 \mathrm{hrs}$ and 7 hrs respectively.

It was interesting to note that in present study more than 50 percent of mothers practiced prelacteal feeds of one sort or the other which includes Cow's milk (39.8\%), Tea (27.2\%), Honey (14.9\%), Goat's Milk $(11.11 \%)$ and Glucose water $(6.89 \%)$ presented in Table.6. Similar results were noticed by Shrivastav et al (1994) Observed that $87.9 \%$ mothers used prelacteal feeds as sugar water (97.5\%). Diluted cow's milk (13.5\%), Honey (7.8\%) \& Milk powder (3.1\%). Honey and diluted cow's milk were commonly used as pre-lacteal feeds in less educated \& low socio-economic class. Whereas artificial milk powder was more common in educated \& high income groups. However, this situation was more common in city compared with the suburban and rural mothers. The prelacteal feeding rates were $62.0 \%, 36.6 \%$ and $39.0 \%$ in city, suburbs and rural areas respectively. The results of the study conveyed that, 41 percent were primiparous mothers and 59 percent were multiparous mothers were observed during the study (table.7). Further results showed that, 60.34 percent of multiparous women (75.5 percent when compared to total) started breastfeeding their babies between half an hour to five hours duration as compared to 57.30 percent of primiparous women (64.3 percent when compared to total) presented in Table.8. However, there was no correlation between parity of mothers and time of 
initiation of breast feeding $(\mathrm{P}<0.001)$. These results are on par with Shrivastav et al (1994) observed that more multiparous mothers (561) succeeded in starting breastfeeding earlier in comparison to the primipara mothers (421).

\section{SUMMARY}

The following Finding was drawn from the study:

(1) Majority of the Mothers $372(74.4 \%)$ started breast feeding their babies between half an hour to five hours duration for exclusive breastfeeding is best.

(2) Only $10.6 \%$ of Mothers put their babies to breast within half an hour.

(3) The time of initiation of Breast feeding in female babies (11.42 percent) were much earlier than the male babies ( 7.83 percent).

(4) 92.5 percent of newborns born by normal vaginal delivery were initiated Breast feeding between half an hour to five hour, as compared to 49.33 percent of babies born by caesarean section.

(5) 52.2 percent of Mothers practiced prelacteal feeds of one sort or the other.

(6) Cow's milk (39.8\%) was most commonly used prelacteal feed followed by Tea (27.2\%), Honey (14.9\%), Goat's Milk (11.11\%) and Glucose water $(6.89 \%)$

(7) 72.5 percent of Multiparous women started breast feeding their babies between half an hour to five hours duration as compared to 64.3 percent of primiparous women.

\section{Conclusion}

The outcome of the study depicts that, the cultural practices like giving pre- lacteals feeds delay the initiation of breast feeding to the newborn. Early initiation of breast feeding was significantly correlated with time. There is also a need for encouragement and support to mothers delivering through caesarean section on the aspect of early initiation of breast feeding during the post partum period. Improving the health of mothers and their children is a primary goal of many developing countries. Therefore, the study suggests that, Protecting, promoting, and supporting breastfeeding is more beneficial and healthy practice for infants, children and mothers, are key strategies to accomplish this goal should be inculcated in a better education approach. Further, the study also suggests that, there are many ways that communities can support mothers and babies that breastfeed, and everyone plays a role for maintaining good health for babies as well as mothers. The study spotlight to inform to help, bring awareness and benefits of breastfeeding practices and supports should be persuade from local and state level health development programmes. It also focus and intervening through public health practitioners in rural and urban places which can scrutinize progress, commemorate successes, and recognize opportunities to inform and work with health professionals, employers, business owners, and community members involved in Institutional deliveries can help in large scale responsiveness. Hence, Health professionals should be trained especially on breast feeding counselling skills. Though the campaign to promote breast feeding in our country is being carried out by national and international agencies, the message should be given more vigorously through Information, Education and Communication (IEC) activities involving the Media as a integral part in transfer of knowledge towards uplift in the society. This can be made only through regular monitoring and by providing essential information on breastfeeding and complementary feeding, counselling and supporting mothers/caregivers in solving common feeding problems.

TABLE : 1

DISTRIBUTION OF TOTAL CASES ACCORDING TO THE SEX OF THE NEWBORN

\begin{tabular}{|c|c|c|c|c|}
\hline \multirow{2}{*}{ Total cases } & \multicolumn{2}{|c|}{ Male sex } & \multicolumn{2}{|c|}{ Female sex } \\
\cline { 2 - 5 } & No. & No. & $\%$ \\
\hline 500 & 281 & 56.2 & 219 & 43.8 \\
\hline
\end{tabular}

TABLE : 2

DISTRIBUTION OF NEWBORNS ACCORDING TO THE SEX AND THE TIME OF INITIATION OF BREAST FEEDING

\begin{tabular}{|c|c|c|c|c|}
\hline \multirow[t]{2}{*}{ Time of initiation of breast feeding } & \multicolumn{2}{|c|}{ Male sex } & \multicolumn{2}{|c|}{ Female sex } \\
\hline & No. & $\%$ & No. & $\%$ \\
\hline With in $1 / 2 \mathrm{Hr}$ & 22 & 7.8 & 25 & 11.42 \\
\hline $1 / 2 \mathrm{Hr}-5 \mathrm{Hrs}$ & 218 & 77.9 & 150 & 68.49 \\
\hline 5Hrs-24Hrs. & 37 & 13.1 & 41 & 18.72 \\
\hline $24 \mathrm{Hrs}-48 \mathrm{Hrs}$ & 2 & 0.71 & 1 & 0.46 \\
\hline $48 \mathrm{Hrs}-72$ & 1 & 0.36 & 1 & 0.46 \\
\hline$>72 \mathrm{Hrs}$ & 1 & 0.36 & 1 & 0.46 \\
\hline Total & 281 & 100 & 219 & 100 \\
\hline
\end{tabular}

$\left(\phi^{2}=5.69, \mathrm{df}=5, \mathrm{p}<0.05\right)$ 
TABLE : 3

DISTRIBUTION OF TOTAL CASES ACCORDING TO TYPE OF DELIVERY

\begin{tabular}{|c|c|c|c|c|}
\hline \multirow{2}{*}{ Total cases } & \multicolumn{2}{|c|}{ NVD } & \multicolumn{2}{c|}{ LSCS } \\
\cline { 2 - 5 } & No. & \% & No. & \% \\
\hline 500 & 413 & 82.6 & 87 & 17.4 \\
\hline
\end{tabular}

DISTRIBUTION OF TOTAL CASES ACCORDING TO TYPE OF DELIVERY

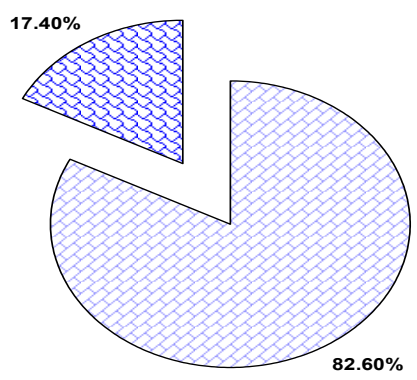

TABLE : 4

DISTRIBUTION OF NEWBORNS ACCORDING TO THE TYPE OF DELIVERY AND TIME OF INITIATION OF BREAST FEEDING

\begin{tabular}{|c|c|c|c|c|}
\hline \multirow{2}{*}{ Time of initiation of breast feeding } & \multicolumn{2}{|c|}{ NVD } & \multicolumn{2}{|c|}{ LSCS } \\
\hline & No. & $\%$ & No. & $\%$ \\
\hline Within $1 / 2 \mathrm{Hr}$ & 52 & 12.6 & 1 & 1.15 \\
\hline $1 / 2 \mathrm{Hr}-5 \mathrm{Hrs}$ & 330 & 79.9 & 42 & 48.28 \\
\hline $5 \mathrm{Hr}-24 \mathrm{Hrs}$ & 25 & 6.0 & 41 & 47.13 \\
\hline $24 \mathrm{Hr}-48 \mathrm{Hrs}$ & 2 & 0.48 & 1 & 1.15 \\
\hline $48 \mathrm{Hr}-72 \mathrm{Hrs}$ & 2 & 0.48 & 1 & 1.15 \\
\hline$>72 \mathrm{Hrs}$ & 2 & 0.48 & 1 & 1.15 \\
\hline Total & 413 & 100 & 87 & 100 \\
\hline
\end{tabular}

TABLE: 5

DISTRIBUTION OF TOTAL CASES ACCORDING TO THE INTRODUCTION OF PRELACTEAL FEEDS

\begin{tabular}{|c|c|c|c|c|}
\hline \multirow{2}{*}{ Total cases } & \multicolumn{4}{|c|}{ Prelacteal feeds } \\
\cline { 2 - 5 } & \multicolumn{2}{|c|}{ Present } & \multicolumn{2}{c|}{ Absent } \\
\cline { 2 - 5 } & No. & $\%$ & No. & $\%$ \\
\hline 500 & 261 & 52.2 & 239 & 47.8 \\
\hline
\end{tabular}

TABLE : 6

TYPE OF PRE-LACTEAL FEEDS GIVEN TO THE NEWBORNS

\begin{tabular}{|c|c|c|c|c|c|c|c|c|}
\hline \multicolumn{2}{|c|}{ Tea } & \multicolumn{2}{c|}{ Goat Milk } & \multicolumn{2}{c|}{ Honey } & \multicolumn{2}{c|}{ Glucose Water } & Cows Milk \\
\hline No. & \% & No. & \% & No. & \% & No. & No. & \% \\
\hline 71 & 27.2 & 29 & 11.1 & 39 & 14.9 & 18 & 6.89 & 104 \\
\hline
\end{tabular}

TABLE : 7

DISTRIBUTION OF TOTAL CASES ACCORDING TO THE PARITY OF MOTHER

\begin{tabular}{|c|c|c|c|c|}
\hline \multirow{2}{*}{ Total Cases } & \multicolumn{2}{|c|}{ Primipara } & \multicolumn{2}{c|}{ Multipara } \\
\cline { 2 - 5 } & No. & \% & No. & \% \\
\hline 500 & 205 & 41 & 295 & 59 \\
\hline
\end{tabular}


TABLE : 8

DISTRIBUTION OF MOTHERS ACCORDING TO THE PARITY AND TIME OF INITIATION OF BREAST FEEDING

\begin{tabular}{|c|c|c|c|c|}
\hline \multirow[t]{2}{*}{ Time of Initiation of Breast Feeding } & \multicolumn{2}{|c|}{ Primipara } & \multicolumn{2}{|c|}{ Multipara } \\
\hline & No. & $\%$ & No. & $\%$ \\
\hline Within $1 / 2$ hrs & 14 & 6.83 & 36 & 12.20 \\
\hline $1 / 2 \mathrm{hr}-5 \mathrm{hrs}$ & 118 & 57.63 & 178 & 60.34 \\
\hline $5 \mathrm{hrs}-24 \mathrm{hrs}$ & 51 & 24.88 & 61 & 20.68 \\
\hline $24 \mathrm{hrs}-48 \mathrm{hrs}$ & 19 & 9.27 & 18 & 6.10 \\
\hline $48 \mathrm{hrs}-72 \mathrm{hrs}$ & 2 & 0.98 & 1 & 0.34 \\
\hline$>72 \mathrm{hrs}$ & 1 & 0.49 & 1 & 0.34 \\
\hline Total & 205 & 100 & 295 & 100 \\
\hline
\end{tabular}

$\left(\phi^{2}=7.13, \mathrm{df}=5, \mathrm{P}<0.001\right)$

\section{Reference}

[1]. Akhter HH, Akhter M and Azad KM, A National Barcline survey to assess the breast feeding practices in Bangladesh. Birperht Publication, Dhaka, Bangladesh, 1998; 64;20.

[2]. Athavale A.V., Athavale, S.A., Deshpande S.G Initiation of Breast feeding by urban women Health and population perspectives and Issues 2004;27(2);117-125.

[3]. Goplana,C. (1989), "Women and Nutrition in India", Some Practical Consideration, Nutrition Foundation of India (NFI) Bulletin, 1989, 10:pp1-4.

[4]. Luke C. Mullany, Joanne Katz, Breast feeding patterns time to initiation and mortality risk among newborns in Southern Nepal. J. Nutr. Mar 2008;138;599-603

[5]. Madhu K, Chowdary S, Masthi R. Breast feeding practices and newborn care in rural areas: A descriptive cross-sectional study. Indian J Community Med 2009;34:243-6.

[6]. Malek Batal and Boulghourjian C (2005). Breastfeeding Initiation and Duration in Lebanon: Are the Hospitals "Mother Friendly"? Journal of Pediatric Nursing. Vol. 20(1) pp. 53-59.

[7]. Srivastava S.P., Vijay Kumar Sharma, Breast feeding pattern in neonates journal of Indian pediatrics 1994; vol31; 1079-82.

[8]. World Alliance for Breastfeeding Action (WABA) annual results based report 2012, "Protecting, Promoting and Supporting Breastfeeding through Human Rights and Gender Equality: A Global project for Coordinated Action to Achieve Millennium Development Goals (MDGs)", 2008-2012. 